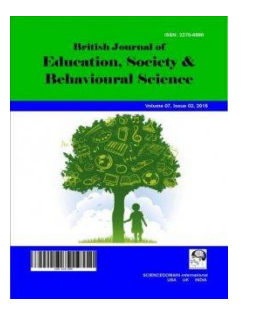

\title{
Locus of Control Synergies in New Language Learning and Cultural Adaptation: A Communication Center Perspective
}

\author{
Roy Schwartzman ${ }^{1 *}$ and Karen E. Boger ${ }^{1}$ \\ ${ }^{1}$ Department of Communication Studies, University of North Carolina at Greensboro, USA.
}

Authors' contributions

This work was carried out in collaboration between both authors. Both authors jointly designed the study. Author KEB facilitated the focus groups and drafted the focus group questions, which author

$R S$ edited. Both authors performed the qualitative analysis. Author RS wrote the first draft of the manuscript. Both authors read and approved the final manuscript.

Article Information

DOI: 10.9734/BJESBS/2017/34367

Editor(s):

(1) Najib Ahmad Marzuki, Professor of Psychology, School of Applied Psychology, Social Work and Policy, College of Arts and Sciences, Universiti Utara Malaysia, 06010 Sintok, Kedah, Malaysia. Reviewers:

(1) Nancy Maynes, Nipissing University, Canada. (2) Barry Chametzky, Pennsylvania, United States. Complete Peer review History: http://www.sciencedomain.org/review-history/19523

Original Research Article

Received 25 $5^{\text {th }}$ May 2017

Accepted $9^{\text {th }}$ June 2017

Published 14 ${ }^{\text {th }}$ June 2017

\begin{abstract}
This study documents how students learning English as a second language exhibit various levels of internal and external locus of control in their learning process. Focus group interviews were conducted with 21 non-native English speakers from seven nations enrolled in an intensive English language learning program at a mid-size research university in the southeastern United States. All participants engaged regularly in conversational practice at the university's oral communication center. Participants were asked about the processes they used for learning English and what their sources of motivation were. Thematic content analysis revealed that internal and external locus of control tended to operate synergistically in the process of learning a new language and adapting to a new culture. Motivation to initiate and persist in new language acquisition emerged from a blend of personal agency, inspiration from family and teachers, and social exigencies. The dynamic interplay between internal and external locus of control challenges common portrayals of these dimensions as antagonistic. Learners often range across levels of internal and external orientations, suggesting need to reconsider characterizations of internality primarily as an enhancer and externality primarily as an inhibitor of learning.
\end{abstract}


Keywords: Locus of control; communication centers; English as a second language; intercultural communication.

\section{ABBREVIATIONS}

EFL : English as a foreign language. Teaching and learning English in a country where English is not the primary language.

ESL : English as a second language. Teaching and learning English in an environment where English is the primary language outside the classroom. Students must adjust to the surrounding culture while acquiring language fluency.

LOC: Locus of control; the degree to which individuals feel they have personal power over influencing events or outcomes.

\section{INTRODUCTION}

Cultural knowledge and linguistic competence play a central role in how well international students adapt to life in the host nation; however, a more fundamental factor influences their ability to adjust. Before international students begin to acquire new cultural knowledge or develop fluency in a new language, they must believe they have the capacity to initiate and follow through with these actions. Thus the construal of personal agency, addressed by the psychological construct known as locus of control (LOC), acts as a prerequisite for cultural adaptation and new language acquisition. Indeed, previous research has identified LOC as a major factor in the ability to adjust well to another culture [1].

\subsection{Justification}

Decades of research across many different cultures has shown that locus of control (LOC), or the degree to which one feels a sense of personal ability to influence outcomes, underlies student willingness to initiate and persist in learning [2]. Originally conceptualized by Julian Rotter [3], LOC serves as a means to identify whether an individual will usually default to believing that she can exert power over her own life (internal) or believing that life is chiefly controlled by outside forces (external). A highly internal LOC can manifest in individuals through behaviors such as taking initiative and responsibility in their actions. Contrarily, a highly external LOC can cause individuals to be more passive and less driven than their highly internal LOC counterparts. Although extensive research has documented the role LOC plays in personal and academic success, thus far minimal attention has focused on how students learning English as a second language exhibit LOC in their learning process.

\subsection{Research Questions}

Newcomers to a culture, especially those acquiring a new language, find themselves at a crucible regarding LOC. Relatively adrift in unfamiliar surroundings, international students in particular face tensions between internal and external LOC. Living separately from their parents and guardians, distant from the familiar expectations and guidance of their caretakers and customs, internationals seeking to acquire fluency in English confront personal, social and intellectual challenges. What motivates international students to continue and, as they advance in fluency, intensify their learning? What factors enhance or impede their acclimation to a different culture and language?

This study addresses these questions from the standpoint of LOC, examining where students find anchors for making decisions about how best to learn and adapt. Specifically, international students were asked to explain how they approach the language learning process. The stakes for these students are high, since insufficient language fluency can halt progress toward academic and professional advancement. The investigation begins with an overview of LOC research related to different cultures, second language acquisition, and intercultural adjustment. To clarify, English as a second language (ESL) refers to instruction of English to non-native speakers in a country where English is the main national language. Thus, students learning English as a second language must be able to adapt to the surrounding culture as well as acquire fluency in the new language. In contrast, English as a foreign language (EFL) refers to instruction in a student's home country without immersion in a native English-speaking environment beyond the classroom. The participants in this study were enrolled in an ESL program, which will be described in detail in a later section.

\subsection{Literature Review}

LOC assumes particular importance in the context of an individual's motivation to initiate and continue to engage with unfamiliar people 
and experiences. LOC refers to the agency that one believes she or he possesses, which allows personal control of the outcomes of interactions and situations she or he encounters. Rotter [3] looked at a distinctive way to measure one's sense of agency through his Locus of Control Scale. The instrument was intended to measure the extent to which individuals believe that their lives are determined through their own motivation and actions (internal LOC) or that they have no real ability to impact the world around them and many interactions are predetermined (external LOC). Levenson [4] examined the LOC scale and developed her own shortened version, based upon the items that more consistently received statistically significant responses, and began focusing on how this role of uncertainty (prevalent in more external LOC scores and especially salient to new language learners) impacted learners' self-efficacy, and thus their motivation to engage with others that they believe to differ from themselves. Additionally, Sapp and Harrod [5] asserted that the element of motivation in Levenson's modified LOC scale was more present in internal LOC scores, which in turn was indicative of these individuals being willing to participate in uncertain situations, whereas those with a more external LOC would be more hesitant. However, upon the creation of Lumpkin's [6] modification of Levenson's LOC scale, the distinctions between internal and external LOC items were condensed even more to provide a more concise measure of where individuals could place themselves on the internal to external LOC spectrum.

A fruitful line of research connects LOC to characteristics of specific cultures, with the degree of internal or external LOC correlated with the cultural values and norms of specific populations [7]. Notably, LOC operates as a construct, not as an invariant trait $[2,8]$. Thus it becomes especially important to explore how individuals adapting to life in a new culture exhibit various levels of internal or external LOC in their cultural adaptation process. In the context of new language acquisition and cultural adjustment, an individual's LOC orientation can inhibit or enhance the transition.

Another expansion of LOC into the international sphere deals with the ability of individuals to have enough self-efficacy to engage in endeavors that require extensive placement in unfamiliar environments. Mueller and Thomas [9] asserted that internal LOC has strong ties with international entrepreneurship, as it is one of the most difficult and highly self-driven fields that requires individuals to step far beyond normal occupational and cultural comfort zones. Research by Krueger and Brazeal [10] provided important insight with the claim that self-efficacy can be fostered in individuals and maintains the ability to be changed throughout one's lifespan; however, the foundation for an individual's entrepreneurial ability begins in one's culture of origin. A highly internal LOC accompanies a decreased aversion to immersion in unfamiliar environments and situations. Other studies extend the application of LOC to various nations and cultures. Jensen, Olsen, and Hughes [11] found that country of origin was more highly correlated with LOC than were other demographic variables. Similar studies across many different regions of the world reach similar conclusions [12]. Such research can provide an important perspective of potential LOC growth and development when someone is immersed in a different culture.

Although ample research has focused on correlations between LOC and various cultures, only a small number of studies have concentrated on how LOC might relate to the process of acquiring a new language and navigating a new culture. These studies tend to examine correlations between LOC and language performance. In Clachar's [8] study of Hispanic adult ESL students, higher internal LOC was associated with greater facility in language acquisition, perhaps reflecting a willingness to risk failure and learn from it. Using quantitative and qualitative analysis, Wood, Saylor, and Cohen [13] found that nursing school students whose native language was not English registered more external LOC. Fakeye [14] found a significant correlation between LOC and achievement in learning English as a second language. Interestingly, the same researcher found no significant correlation between ESL performance and whether LOC was internal or external. Similarly, Nodoushan [15] found that the kind of LOC (internal vs. external) did not correlate with acquiring proficiency in English as a second language. These studies raise questions regarding whether internal LOC is uniformly beneficial in English language learning contexts. The authors of the present study investigate the complexities of how LOC operates in learning a new language and culture. Extant studies offer useful insights; however, the role that LOC actually plays in the learner's own process of communicative adaptation and language learning remains relatively 
unexamined. This gap in the literature offers an opportunity to explore LOC on the learner's own terms, as expressed in the way learners themselves characterize the process of English language acquisition.

\section{METHODOLOGY}

The current study was conducted at a doctorategranting research university (enrollment 18,500) in the southeastern United States. The site is designated a Minority Serving Institution, with an undergraduate student body comprised of approximately $27 \%$ African Americans and $7 \%$ Hispanic or Latino/Latina Americans. The participant pool consisted of international students enrolled in the Interlink Language Center programs. Interlink provides a structured curriculum for internationals to learn English so they can acquire sufficient proficiency to matriculate as full-time students or to pursue employment. As part of the Interlink programs, students are required to practice their English conversational skills in sessions at the University Speaking Center, a communication center that offers student peer tutoring in oral communication (public speaking, conversations, etc.). Student tutors facilitate these conversation sessions, which usually involve several Interlink students in thematic discussions or verbal games as conversational practice. These verbal interactions offer low-stakes (ungraded, although required) regular verbal interactions facilitated by native English speakers who work as student peer tutors at the communication center. The conversational practice sessions provide an important component of Interlink's overall objective to improve language proficiency through regular practice using English in dynamic verbal interactions.

Participants were recruited in person when they visited the communication center for the conversation sessions. In addition, communication center staff personally visited Interlink classes to solicit volunteers. The recruitment script, focus group protocol, and all other procedures received appropriate approval from the university's Institutional Review Board.

Focus groups were employed as the method of data collection. This approach offered key advantages relevant to the study and participants. First, interactions among the participants enabled "complementary interactions" that could provide richer data than individual interviews [16]. Participants could play off each other's comments, generating richer explanations and more extensive examination of their approaches to learning. Second, the presence of other English language learners enabled the participants to observe and comment on the similarities and differences among their learning techniques. Finally, the interactive nature of the focus groups, conducted in English, generated enthusiastic participation because students embraced the opportunity to gain additional conversational practice.

The choice of focus groups arose out of a desire to delve more deeply into how students conceptualized and characterized their own educational processes. The overwhelming majority of research on LOC quantitatively measures an individual's LOC orientation and generally assesses the correlation between this data and some other data related to learning (such as scores on English proficiency tests). While such information is useful, it does not tend to explore how the students themselves actually use LOC in their learning process. The focus groups enabled the students to explain that process on their own terms, generating an emic perspective absent from much quantitative research [17].

Focus group interviews were conducted with a total of 21 international students (11 male, 10 female) from seven nations participating in the focus groups. The native countries of participants were: Saudi Arabia (9), China (7), and one student each from Mexico, Venezuela, Angola, Vietnam, and South Korea. Seven focus groups were conducted, with each focus group consisting of two to six (mean = 2.86) participants. The average focus group size was small due to challenges in coordinating participants' schedules. The small group size also had an intentional aspect. As with small classes, restricting the group size encouraged greater participation by reducing the likelihood that participants with more advanced English language skills would dominate the conversation. The focus groups were facilitated by a managing consultant at the communication center. The facilitator had previously worked with some of the participants during their regular English conversation practice sessions at the communication center. This familiarity with the students and with Interlink helped elicit more indepth interactions, since some rapport already had been established.

The focus group protocol centered on five openended questions dealing with how the participants preferred to learn English and which 
learning techniques worked best. The complete focus group protocol appears in the Appendix. These stimulus questions served as conversation starters and assisted in guiding participants toward discussing who or what exercised primary agency in enabling someone to learn a new language.

The focus group sessions were audio recorded, then transcribed verbatim. The transcriptions yielded 68 pages of single-spaced text, totaling 21,467 words. Qualitative thematic content analysis was conducted, since using themes as the unit of analysis would circumvent idiosyncratic phrasing of participants' comments. Thematic analysis offered a particularly appropriate approach in this case, since participants at different levels of English proficiency might use substantially different terminology to express the same concept.
Content was assigned to one of four mutually exclusive pre-set categories [18] derived from Rotter's original binary LOC scale. This binary coding method (internal/external) corresponds to the original and updated LOC instrument developed and refined by Rotter $[3,19]$ as well as that of Wolfgang and Weiss [20]. The latter instrument has been used for assessing the role of LOC in English language acquisition [8]. The categories, their definitions, and examples of content within each category appear in Fig. 1.

Two researchers coded the content independently, with discrepancies regarding assignment to categories resolved through discussion that yielded full agreement on the classifications. Assignment to categories was governed by criteria to distinguish internal from external, with determination of reference to self or others gleaned from explicit textual content mentioning self or others.

\begin{tabular}{|c|c|}
\hline $\begin{array}{l}\text { Perception of others as } \\
\text { internally controlled } \\
\text { Definition: Other people's } \\
\text { outcomes result } \\
\text { from their own abilities, } \\
\text { characteristics, or efforts } \\
\text { Example: "My friend became } \\
\text { fluent in English after only } \\
\text { six months because she } \\
\text { practiced conversations for } \\
\text { five hours daily." }\end{array}$ & $\begin{array}{l}\text { Perception of others as } \\
\text { externally controlled } \\
\text { Definition: Other people's } \\
\text { outcomes are controlled by } \\
\text { powerful others or by } \\
\text { impersonal guiding forces } \\
\text { (luck, fate, the system). } \\
\text { Example: "He is very lucky to } \\
\text { be born in America, } \\
\text { everyone around him speaks } \\
\text { English." }\end{array}$ \\
\hline $\begin{array}{l}\text { Perception of self as } \\
\text { internally controlled } \\
\text { Definition: You and your own } \\
\text { abilities, characteristics, or } \\
\text { efforts determine how you } \\
\text { fare. } \\
\text { Example: "I could learn } \\
\text { English faster if I spent more } \\
\text { time with native English } \\
\text { speakers." }\end{array}$ & $\begin{array}{l}\text { Perception of self as } \\
\text { externally controlled } \\
\text { Definition: Personal } \\
\text { outcomes are controlled by } \\
\text { powerful others or by } \\
\text { impersonal guiding forces } \\
\text { (luck, fate, the system). } \\
\text { Example: "I'm just not good } \\
\text { at learning languages." }\end{array}$ \\
\hline
\end{tabular}

Fig. 1. Categorization scheme for thematic content analysis of focus groups 
Despite the abundance of qualitative studies concerning LOC, there remains little transparency in how qualitative data from participants get categorized as predominately internal or external. To operationalize LOC, the authors of the present study identified several discursive characteristics associated with remarks that had been encoded as internal or external in data from the focus groups. Using the techniques of grounded theory [16], the coders sought common themes among the responses categorized as predominately internal or external. Working back and forth between the categories and the content, several discursive qualities of the manifest content characterized internal or external orientation. Table 1 summarizes the discursive qualities sufficient to identify an utterance as exhibiting predominately internal or external LOC. To qualify as internal, the discourse employed active voice, referred to goals or processes initiated or implemented by the speaker, or identified the speaker as the decision-making agent. Externally oriented discourse employed passive voice, referred to goals or processes initiated or implemented by others, or identified someone other than the speaker as the decision-making agent.

\section{RESULTS AND DISCUSSION}

The participants' descriptions of their learning processes revealed that internal and external LOC operated synergistically. Weaving back and forth between internal and external LOC throughout their conversations, the Interlink students described and demonstrated an ability to construct specific situations as opportunities or as barriers to improving linguistic and cultural proficiency. Far from uniformly internal or external, the content of the focus group conversations reflected a strategic approach to learning a new language rather than a categorical stance as an active, internally driven learner or as a more reactive student preferring more guidance. For the Interlink students, LOC represented less of a static, consistent orientation than a repertoire of ways to encounter the language learning process. Particular episodes, such as encounters with a difficult lesson or a challenging teacher, activated an LOC orientation as a coping mechanism.

These LOC dynamics can become rather complex, but they demonstrate the richness of the learning process. A Saudi student, for example, said that she relied on her teachers to encourage her to practice speaking English. The teacher acted as the agent instigating the student's search for opportunities to practice. Two other female Saudi students echoed the need for teachers to stimulate the urge to practice. Yet, these students expressed some movement beyond passive compliance with an external authority figure. Although they had been urged to practice, they had to take the initiative to find or create practice sessions. All three students concurred that they "need someone" to "advise" them about opportunities to practice conversing. Toward the end of the focus group, the conversation took a decidedly more internal LOC regarding the learning process. One female Saudi student noted, "I have selected a goal [to learn English] and I push myself." At this point, she stated ownership of the goal that originally required the teacher's directions to implement.

Experiences with teachers could shift the expressed LOC orientation toward internal or external. A female Chinese student observed that the quality of a teacher could stimulate a reactive LOC response in either direction. She noted that in middle school she quickly

Table 1. Criteria for coding responses

\begin{tabular}{|c|c|}
\hline $\begin{array}{l}\text { Response characteristics: } \\
\text { Internal locus of control }\end{array}$ & $\begin{array}{l}\text { Response characteristics: } \\
\text { External locus of control }\end{array}$ \\
\hline Active voice & Passive voice \\
\hline $\begin{array}{l}\text { Person discussed appears as agent of } \\
\text { action (grammatical subject) }\end{array}$ & $\begin{array}{l}\text { Person discussed appears as acted upon by other } \\
\text { people or forces (grammatical direct or indirect } \\
\text { object) }\end{array}$ \\
\hline Plan or initiate action & Follow instructions, conform to what others want \\
\hline Invent, adapt, or customize processes & Obey established procedures \\
\hline $\begin{array}{l}\text { Attribute outcomes to individual (in)actions, } \\
\text { personal efforts }\end{array}$ & $\begin{array}{l}\text { Attribute outcomes to external conditions, inherent } \\
\text { character, other people }\end{array}$ \\
\hline $\begin{array}{l}\text { Difficulties are barriers to overcome or work } \\
\text { through (trigger greater personal effort) }\end{array}$ & $\begin{array}{l}\text { Difficulties confirm pre-existing attitudes or } \\
\text { conditions (reflect the nature of things) }\end{array}$ \\
\hline
\end{tabular}


developed English language skill "because I had a very good English teacher." Subsequently in high school her motivation to practice waned and her skills atrophied. "I didn't like my English teacher, so I didn't want to practice more." In both cases this student exhibited an external orientation, attributing responsibility to the teacher for the student's own level of accomplishment. The outcome in the first case, however, reflected an expression of a desire to learn as demonstrated in her willingness to voluntarily put in the required time to practice. The inspirational middle school teacher in effect relinquished control when she triggered the student to acknowledge and embrace her own ability. "So she encouraged me; she told me I could do it." The willingness and ability to cede control distinguishes the teacher as motivator from the teacher as master. Another female Chinese student offered a perspective quite different from her cohort: "I need for someone to force me to learn."

A primary driver for both of these women to continue their learning was to maximize their authenticity as Americans. As one of them affirmed, "I want to have to try my best to have very good pronunciation to sound like a real American." This kind of statement reflected a richly textured LOC orientation. To some extent, it expressed a type of passivity, an acceptance of compulsion ("have to try") characteristic of external LOC. Yet, it also embraced a personal desire for belonging in her new surroundings.

A male Venezuelan student's comment also reflected a dynamic dialectic between internal and external LOC. This student found motivation in his younger brother, who wanted to emulate him. That external driver ignited an internal imperative to learn English. "So this is more motivation for me-because I want to be good at something, for him." Such phraseology veered away from an imperative ("I must") and embraced a source of inspiration. The same student also acknowledged the value of external validation even if the impetus for his accomplishments were within himself. "Also-my family - they say, 'I'm so happy because you are good by now.' So, this is good." For this student, personal confidence had to be initiated externally to activate his own perseverance. "For me, myself, I can't do it. I need my family or someone to tell me: "You can do it."'

Sometimes personal comparisons with other learners would shift LOC orientation. Some of the most dramatic assertions of external LOC occurred when participants compared themselves to especially adept language learners. A Saudi male referred to some "gifted" language learners, then immediately contrasted them with his own inferior skills. These other students are "gifted so they can learn fast or learn languages faster. Also, they may practice more or they have good techniques that I don't have." Comparison with more accomplished students quickly shifted this student's selfreferences to a deficit mode, focusing on what he did not have or could not do. He continued: "So, gifted people can learn faster. That's the difference." Another Saudi male immediately added, "Yeah, because I think they can see more vocabulary words. More than a natural human being can." These kinds of remarks illustrate how external comparisons can easily turn pernicious. If this line of thinking were extended and reinforced, it could foster a mentality of self-doubt and discouragement. If those adept at learning languages are preternatural, then those who are simply "normal" suffer from innate flaws.

By contrast, a Mexican male student succinctly summarized what encouraged him to continue trying to master English. Referring to his interactions with native English-speaking student tutors in the communication center, he said: "They are so patient with the person. All the time." Learning in an environment that permitted and tolerated mistakes enabled this student to avoid internalizing and essentializing his errors as personal shortcomings.

Some students remarked on how helpful a collaborative environment was for encouraging them to practice and for learning. Instead of comparing themselves to others who outperformed them, these students noted that finding common cause with others improved their comfort level in a new culture. A male Saudi student explained how, after initial reticence, he built the confidence to initiate conversations in English. "But, now it's okay. Now it's okay. Because, like he said-I know everybody in the [Interlink] classroom. They are my friends. They are-we are here for the same thing: to learn English." The presence of a cohort facing the same challenge of cultural adjustment apparently generated a collective willingness to persevere. A Venezuelan male attributed his persistence directly to membership in Interlink. "Well, me, when I came to the U.S., I was scared and I learn English. Interlink can help me to learn and improve the English. This is the thing that's 
holding me here." Such a statement oscillates along the internal/external LOC continuum. Does Interlink's "holding" this student in the United States constitute support or bondage? In context, the student clearly referred to the program as supportive, but does support carry the same connotations and implications as external LOC? Must support connote relinquishing control or encouraging passivity?

Most of the existing research on LOC does not appear to address this phenomenon. Would embracing a collective represent an externalization of LOC? In some sense, it would seem that the individual would surrender some personal accountability for outcomes. On the other hand, the LOC might actually shift toward internal to the extent that the individual acquires a greater sense of agency within a collective. Rather than an agent in itself, the collective may serve more as a catalyst for personal initiative and accomplishment.

Economic exigencies played a major role in driving these students to learn English. Although several participants stated that the requirement to learn English for a profession was, as an Angolan female said, "why I motivate myself," the economic factor made English compulsory. This student immediately added, "If I want to get a good job, I must speak English." Again, however, external compulsion blended with internal desire. The necessity of English fluency provided a condition for the fulfillment of her personal objective. Internality and externality were more intertwined than antagonistic. A Saudi male in the same focus group expressed a similar interface between preference and necessity. "I want to have a good job, and I'm looking for a good future. So if you want to have a good job, you have to at least have two languages." Another Saudi male concurred: "So, I find that I have to study English and I have to complete [the Interlink curriculum] to have a raise." Apparently some skills were mandatory to open up the desired options. Recast in the vocabulary of LOC, fulfilling externally imposed requirements could pave the path to achieving personal (internal) objectives.

\subsection{Limitations}

This study has some limitations that deserve consideration. First, it is unclear how far findings should be extrapolated from these relatively small populations. Although the participants were culturally and nationally diverse, some regions and cultures had minimal representation. This inability to attribute LOC to specific national or cultural variables, however, may not constitute a serious limitation. An extensive meta-analysis of 70 studies dealing with LOC revealed no consistent cross-cultural differences or patterns in LOC [21]. The shared experience of learning a new language, specifically English, assumes paramount importance in this study.

Second, the focus group conversations were relatively artificial, so the content of conversation may not accurately reflect the ordinary communicative content of the participants. A more natural communicative interaction, such as a conversation stemming from a pre-existing event or concern that brought participants together and catalyzed the interaction, might generate more authentic communication and therefore more generalizable findings.

Third, it remains unclear whether native language or cultural identity acts as an independent or primary variable affecting perceptions of LOC. Given that lower socioeconomic class persistently links to more external LOC [2], various demographic factors unrelated to internationalism or country of origin may have acted as confounding factors.

Fourth, assessing LOC from verbal conversation rather than self-reports could raise some concerns. Some of the communication patterns within the focus groups might have arisen more from the interpersonal dynamics of the group than from the individual's actual level of internal or external LOC. A form of social desirability bias or cultural adaptation could have urged participants to express the LOC they believed others expected to hear. For example, in a mixed-gender group from a highly patriarchal culture, ordinarily highly internal LOC women might have behaved as highly external LOC in the presence of males. In addition, the gender, native English fluency, or other demographic characteristics of the facilitator may have affected the way participants expressed themselves. Since the conversation was elicited rather than observed as a spontaneous interaction in a natural context, some vestiges of a Hawthorne effect may have occurred.

\subsection{Implications}

Ideally, future studies should anticipate and preempt such difficulties by employing a design that includes both self-reports based on previously 
validated LOC measures and observations of verbal conversational performance in natural contexts. Future studies should take the limitations of each method-self-reports and observed utterances-into account and proceed cautiously when forming conclusions based solely on self-reports or observed performance. Important insights about cultural adaptation and expressive authenticity might arise from comparing publicly performed LOC with personally perceived LOC.

The developmental trajectory of LOC during and after acquiring competency in a new language deserves further study. Navigating multiple cultures and languages may enable individuals to become more adaptable in their LOC, tailoring it to fit the cultural environment [22]. This finding suggests that the development of LOC may not be unidirectional toward internal or external for new language learners. While more internal LOC does contribute to the initiative to learn and persevere, cultural adaptability enables the skilled multicultural communicator to adjust LOC to fit social customs and expectations [23].

\section{CONCLUSION}

Overall, the findings of this study render the landscape of LOC far more complex and nuanced than most previous research might indicate. The bulk of research on LOC seems to equate internal orientation with academic progress and personal success. In the context of non-native language acquisition, however, the discourse of language learners reveals a complicated interplay between internal and external LOC orientation. A more internal LOC is reflected in the personal desire to drive past difficulties in acquiring fluency and embrace opportunities to practice using and listening to the new language.

A more external LOC, however, does not always accompany expressions of frustration or helplessness. Instead, deference toward native or more fluent speakers generates a healthy humility reflected in the willingness to acknowledge one's own limited fluency and attend more carefully to others who have mastered the language. Another benefit of external LOC arises regarding cultural adaptability. Many of the participants acknowledged that their new cultural milieu placed unfamiliar constraints on their actions. Greater linguistic fluency would enable them to act appropriately, doing the correct things in various contexts and thus abide by cultural expectations. The internal drive to become fluent in a new language also requires a willingness to cede control in order to listen and learn more thoroughly.

The robust interplay between internal and external LOC observed among international students in this study raises important issues that merit further consideration. Previous research across many different countries and cultures has found that LOC orientation correlates with the level of individualism/collectivism [7]. Specifically, members of more individualistic cultures (e.g., the United States) register far more internal LOC than members of more collectivistic cultures (e.g., Japan and China), who score more highly external on quantitative LOC measures. These cultural differences suggest caveats about too categorically associating internal LOC with academic achievement and new language acquisition. Perhaps a highly internal LOC would prove advantageous in individualistic educational systems, but that does not automatically render an internal orientation a universal educational advantage. As the current results showed, many behaviors associated with external LOC, such as deference to family or reluctance to initiate conversations until teachers approved the student's pronunciation, can facilitate rather than inhibit progress. The unqualified linkage of internal LOC with high student performance at best may misrepresent the role LOC plays in learning. At worst, it may reflect cultural biases that privilege internal LOC and associated cultural tendencies, such as individualism, while underestimating the significance of external LOC in learning.

The rich intertwining of internal and external LOC in the interactions within the focus groups points to several areas of LOC that need further clarification. LOC may require greater refinement as a construct, especially regarding the nature of internal and external LOC. The construct does not offer a clear distinction between affiliation and dependency when discussing external LOC. The bulk of research tends to treat external LOC in educational contexts as distinctly negative, an inhibition to learning and to personal development. The discourse of the participants in this study raises intriguing possibilities for reframing not only external LOC, but also the relationship between internal and external LOC.

Internal and external LOC operate along a continuum, so student communication and behavior range across degrees of internality and externality [24]. The results of the current study 
demonstrate how internal and external LOC can operate synergistically as well as antagonistically in the ways students approach learning a new language. The focus group discussions provide insight from students themselves regarding how they manage the relationship between internal and external LOC when faced with the challenge of adapting to a new communication environment. Perhaps the most adept students combine intrepid self-direction with gracious acceptance of direction from others.

\section{ACKNOWLEDGEMENTS}

The authors gratefully acknowledge the cooperation and support of the Interlink Language Center at the host university. This project was funded by a Globally Engaged Undergraduate Research and Creativity Award from the University of North Carolina at Greensboro Undergraduate Research, Scholarship and Creativity Office.

\section{COMPETING INTERESTS}

Authors have declared that no competing interests exist.

\section{REFERENCES}

1. Tucker MF, Bonial R, Lahti K. The definition, measurement and prediction of intercultural adjustment and job performance among corporate expatriates. International Journal of Intercultural Relations. 2004;28(3/4):221-251.

2. Lefcourt HM. Locus of control: Current trends in theory and research. $2^{\text {nd }}$ ed. New York: Psychology Press; 2014.

3. Rotter J. Generalized expectancies for internal versus external control of reinforcement. Psychological Monographs: General and Applied. 1966;80(1):1-28.

4. Levenson $\mathrm{H}$. Activism and powerful others: Distinctions within the concept of internalexternal control. Journal of Personality Assessment. 1974;38(4):337-383.

5. Sapp SG, Harrod WJ. Reliability and validity of a brief version of Levenson's locus of control scale. Psychological Reports. 1993;72(2):539-550.

6. Lumpkin JR. Establishing the validity of an abbreviated locus of control scale: Is a brief Levenson's scale any better? Psychological Reports. 1988;6(2):519-523.

7. Smith $P$, Trompenaars $F$, Dugan $S$. The Rotter locus of control scale in 43 countries: A test of cultural relativity. International Journal of Psychology. 1995; 30(3):377-400.

8. Clachar A. Dimensions of locus of control: Exploring their influence on ESL students' interlanguage development. Issues in Applied Linguistics. 1992;3(1):7-41.

9. Mueller S, Thomas A. Culture and entrepreneurial potential: A nine country study of locus of control and innovativeness. Journal of Business Venturing. 2001;16(1):51-75.

10. Krueger N, Brazeal D. Entrepreneurial potential and potential entrepreneurs. Entrepreneurship Theory and Practice. 1994;18(3):91-104.

11. Jensen L, Olsen J, Hughes C. Association of country, sex, social class, and life cycle to locus of control in western European countries. Psychological Reports. 1990; 67(1):199-205.

12. Smith A, Hume E, Zimmermann R, Davis, A. The global significance of locus of control in ethical decision making: A multicountry examination of university students. Journal of College Teaching \& Learning. 2007;4(2):7-12.

13. Wood A, Saylor C, Cohen J. Locus of control and academic success among ethnically diverse baccalaureate nursing students. Nursing Education Perspectives. 2009;30(5):290-294.

14. Fakeye DO. Locus of control as a correlate of achievement in English as a second language in Ibadan. Journal of International Social Research. 2011;4(17): 546-552.

15. Nodoushan MS. The impact of locus of control on language achievement. International Journal of Language Studies. 2012;6(2):123-136.

16. Lindlof TR, Taylor BC. Qualitative communication research methods. $2^{\text {nd }}$ ed. Thousand Oaks, CA: Sage; 2002.

17. Patton MQ. Qualitative research and evaluation methods. $3^{\text {rd }}$ ed. Thousand Oaks, CA: Sage; 2002.

18. Neuendorf KA. The content analysis guidebook. Thousand Oaks, CA: Sage; 2002.

19. Rotter J. Some problems and misconceptions related to the construct of internal versus external control of reinforcement. Journal of Consulting and Clinical Psychology. 1975;43(1):56-67.

20. Wolfgang A, Weiss DW. A locus of control and social distance comparison of 
Canadian and West Indian-born students. International Journal of Intercultural Relations. 1980;4(3-4):295-305.

21. Hui, $\mathrm{CH}$. Locus of control: A review of cross-cultural research. International Journal of Intercultural Relations. 1982; 6(3):301-323.

22. Garza RT, Romero GJ, Cox, BG, Ramirez M. Biculturalism, locus of control, and leader behavior in ethnically mixed small groups. Journal of Applied Social Psychology. 1982;12(3):237-253.
23. McCabe KM, Goehring K, Yeh M, Lau AS. Parental locus of control and externalizing behavior problems among Mexican American preschoolers. Journal of Emotional and Behavioral Disorders. 2008; 16(2):118-126.

24. Fazey DA, Fazey JA. The potential for autonomy in learning: Perceptions of competence, motivation and locus of control in first-year undergraduate students. Studies in Higher Education. 2001;26(3):345-361. 


\section{APPENDIX \\ FOCUS GROUP PROTOCOL}

\section{Warm-Up and Orientation}

Thank you for agreeing to participate in this focus group. The purpose of this focus group is to understand what role the Speaking Center plays in developing your communication skills in a new culture. We want to stress that all your responses and comments will remain anonymous. We will eliminate all personally identifying information, including your name, when we write down our records of this session. We know that you are very busy and we appreciate you being here.

\section{Introductions}

We are interested in hearing from everyone and we hope that you will all actively participate in the discussion. We would like to take a few moments for introductions. Could you please introduce yourself by giving us your first name and your country of origin?

Please share your thoughts about the following matters.

\section{Locus of Control and Communication Competencies}

Gauging Internal Locus of Control

1. How have you motivated yourself to learn English?

Probes:

A. How often do you practice speaking English?

B. Why is it so important to you to be fluent in English?

Gauging External Locus of Control: Powerful Others

2. How have other people (friends, classmates, teachers) helped motivate you to learn English?

Probes:

A. What have they done to personally help you learn English?

B. How well do you think you could have learned English without the help of these other people?

Gauging External Locus of Control: Fate or Chance

3. What makes some people better (or worse) at learning English than others?

Probes:

A. Is the ability to learn another language a natural talent you are born with? Why or why not?

B. How much does luck or fate affect your ability to learn English?

Speaking Center and Communication Competencies

4. What role does the Speaking Center play in developing your English language skills?

Probes:

A. What has the Speaking Center done that helped you the most? 
B. What has the Speaking Center done that helped you the least?

C. How else could the Speaking Center assist you in improving your English?

\section{Summative Locus of Control Assessment}

5. Overall, what plays the biggest role in your learning about the English language and American culture: your own efforts, help from others, or factors beyond your control (such as natural ability)?

Probe: Why do you think that is the biggest factor?

\section{Conclusion}

Thank you for participating in this focus group. To repeat, your comments will be anonymized in the transcription process. If you have any follow-up questions regarding what we have discussed, please do not hesitate to contact us.

(c) 2017 Schwartzman and Boger; This is an Open Access article distributed under the terms of the Creative Commons Attribution License (http://creativecommons.org/licenses/by/4.0), which permits unrestricted use, distribution, and reproduction in any medium, provided the original work is properly cited.

Peer-review history:

The peer review history for this paper can be accessed here: http://sciencedomain.org/review-history/19523 